\title{
Fair pricing: A framework towards sustainable life insurance products
}

\author{
Agus Setiawan $^{a^{*}}$, Sugiarto ${ }^{\mathrm{b}}$, Grace Shinta S. Ugut ${ }^{\mathrm{c}}$ and Edison Hulu ${ }^{\mathrm{d}}$
}

${ }^{a}$ Doctoral Program, Universitas Pelita Harapan, Indonesia

${ }^{b}$ Faculty member of Universitas Prasetiya Mulya, Indonesia

${ }^{c}$ Dean of Business School, Universitas Pelita Harapan, Indonesia

${ }^{d}$ Lecturer, Graduate School, Universitas Pelita Harapan, Indonesia

\section{H R O N I C L E \\ A B S T R A C T}

Article history:

Received: July 25, 2020

Received in revised format:

September 302020

Accepted: October 23, 2020

Available online:

October 23, 2020

Keywords:

Fair Pricing

Unit Linked

Conditional Tail Expectation

Stakeholder Pricing

\begin{abstract}
This research aims to fill the gap in sustainable insurance product study. The central research question of this research is how to develop a fair pricing framework in order to design a sustainable financial product. Current profit testing method is arguably lack of policyholder considerations. The profitability decision under current method only considers profit margin for company. There is no profitability measurement for policyholder. To improve fairness under current pricing, the proposed study proposes a concept of equity in risk between company and policyholder. In order to establish equity in risk, profitability for policyholder needs to be defined and risk measure Conditional Tail Expectation (CTE) for company and policyholder is proposed as a solution. Fairness is achieved if CTE between company and policyholder falls within certain range. CTE generated under new framework could be used as a reference point to all stakeholders to assess the fairness of Unit Linked price. The target population for the study was any regular premium Unit Link product. This research used simple random sampling. From the population consisting of 34 companies 20 samples were drawn. Data is taken from the Indonesian Financial Service Authority. The data used is from the time period between 1 January 2015 and 30 June 2019. Using the CTE, this study finds that most of the Unit Linked pricing are far from fair. It is recommended that companies could be more efficient in their operating and distribution cost in order to be fairer to policyholder and therefore will make the product more sustainable.
\end{abstract}

(C) 2021 by the authors; licensee Growing Science, Canada

\section{Introduction}

Life insurance as part of financial industry has to introduce a product in proper price in order to survive in their business. There are guidelines, regulations and several best practices to be adopted when company exercises the product pricing process. However, essential question: Would you sell this product to your mom or dad? is frequently omitted or considered. Parallel to this question is the fact that Financial Services is the least trusted across industries according to global survey by Edelman Trust Barometer from 2012 to 2019. Guideline, regulation and best pricing practices often centered around company interest and is usually based on financial consideration. The question challenges the life insurance companies to broaden their pricing strategy to consider other factors besides financial. Taking a further thinking, the question also leads companies to consider a more sustainable approach towards their pricing strategy, such as: environment, social and governance (ESG) or Triple Bottom Line

* Corresponding author. Tel.: +622181281896881

E-mail address: stw_agus@yahoo.com (A. Setiawan) 
(TBL) concerns. Sustainable product will exhibit fair pricing which considers fairness to all stakeholders. It also considers other aspects besides financial. Hallstedt (2017) suggests to address other aspects as early as in the product development stage.

This research will try to fill the gap and answer previous questions by introducing a method of pricing that would consider the other stakeholders in the life insurance business. Whereas there are many stakeholders, this research limits the stakeholders into company shareholder, regulators, distribution channels and customers. If company could be fair to all the fours stakeholders then arguably it has address ESG or TBL concerns. Proper governance and fair treatment to all the stakeholders would result in much less exploitation of resources or increase the use of more green investment and activities (Gerald, 2018). People will be happier to deal with more ethical companies. Addressing sustainability is even more important because there are many researches and surveys that find that Millennial generation concern about this. The Millennial Impact Report 2017 shows that $87 \%$ of Americans will buy a product with company that cares about CSR, an activity that is closely related to sustainability. Nielsen 2015 survey report reveals that $73 \%$ of Millenial are willing to spend more on a product if it comes from a sustainable brand. Finally, the adoption of United Nation resolution about 17 Sustainable Development Goals by 193 countries show that sustainability is the way to achieve a better future. The importance of developing a sustainable financial product has long been recognized by the industry despite its slow development (Weber, 2014; Hira, 2012). This research will propose a fair pricing as a framework to develop sustainable product. Many researchers have found a close relationship between fairness and sustainability. If you price your product fairly to all stakeholders, your product will be more likely to be sustainable. The fair pricing concept will be illustrated using Unit Linked insurance product. This product is the most saleable product in Indonesia for the last 5 years and is still projected to be the dominant product in the next 5 years. Unlike pure insurance products, Unit Linked combines both insurance and investment in a single integrated product. The investment risk is borne by the policyholder. The integration of insurance and investment (including the risk) makes it difficult to justify the fairness of the charges applied to the premium. This research aims to address the fairness of the pricing of Unit Linked given that policyholder needs to borne the investment risk. Last but not least, linking to the digital era now the framework to generate fair pricing for Unit Linked product will help company and policy maker to launch this product on line rather than requiring it through advice selling (Reisman, 2019). The reason is that the framework has been developed to address most of the fairness and sustainability concern related to all stakeholders especially the customer.

\subsection{Research Objectives and Questions}

This study poses the following central research question: "How to develop a fair pricing framework in order to design a sustainable financial product". A contextualization of three research questions are described below:

- What is current practice to price Unit Linked product?

- What are the fairness problems in current pricing practice?

- What risk measure reference point should be used to address fairness between policyholder and company?

The purpose of this research is to develop a fair pricing framework in order to create a sustainable Unit Linked product. Therefore, the objectives include the following:

- To explore current practice to price Unit Linked product,

- To identify fairness problems in current pricing practice,

- To develop risk measure as a reference point to address fairness between policyholder and company.

\subsection{Significance of Study}

This study has novelties in three ways:

Theory: This study has compiled a comprehensive grand theory underpinning the sustainability for financial products and fair pricing from the recent and most significant literatures. Sustainability theory starts from Shareholder Wealth Maximation theory (Friedman, 1962) as the lowest level of sustainability to Enlightened Stakeholder theory (Jensen, 2001). Fair pricing as a key element of sustainability will be discussed through Equity theory and the two major famous concepts, i.e. Procedural fairness (Chong, 2015; Ferguson, et al., 2014; Zhang, 2015) and Distribution fairness (Diller, 2008; Krawczyk, 2011; Kamas \& Preston, 2012; Lucas, 2009). By reviewing and summarizing the theoretical arguments between sustainability and fair pricing, including identifying potential theoretical and research gaps, this study aims to develop theoretical framework to price Unit Linked product fairly and therefore will make the product sustainable. This study will overcome drawbacks in current pricing method which lacks of stakeholder point of view and therefore fairness. Study will introduce the concept of Stakeholder Pricing to the Unit Linked pricing theory.

Practice: the high sample proportion of the primary data that has been collected and processed for the empirical analysis in this study will not only provide detailed information on product specification and ways companies price the product, but also provide evidences that companies frequently price the product through profit testing method from the company point of view. Conclusion drawn from the sample data will provide valuable information for society, actuary, life insurance/financial industries 
and regulators. This study will also provide insight to actuary or other professions to act ethically and professionally when price or develop a product by enlightening the current profit testing method. The framework developed here will eliminate information asymmetry in the Unit Linked price fairness assessment. Since the framework will generate a fair price for Unit Linked, this product could then be sold through internet. This will foster the growth of this product which could help addressing financial needs and planning for society.

Regulators. This framework developed in this study if it is implemented as a government regulation will advance corporate transparency on sustainability. Currently the fair pricing framework on Unit Linked pricing is very rare if any. In line with the Global Reporting Initiative, policy makers must promote of non-financial (including ESG) information in their annual accounts. There is an increasing demand for sustainability information and initiatives such as Principle of Sustainable Insurance report. This framework could fulfill such demands and requirements. To help with the implementation, the CTE figures should be made transparent as early as in the product development submitted to the regulator as well as in the selling process.

\section{Literature Review}

Literature reviews are organised to support the theoritical arguments to develop the fair pricing framework. First, the review starts with theory of sustainability in general. Sustainability or sustainable development has been defined in many ways, but the most frequently quoted definition is from Our Common Future, also known as the Brundtland Report: "Sustainable development is development that meets the needs of the present without compromising the ability of future generations to meet their own needs" (WCED, 1987, p.43). The sustainability concept has been applied in business to become Business Sustainability. Business sustainability gains an increasing consideration after 2007-2009 global financial crises. It is generally meant to ensure the long-term continuation of organizations and their accountability to various stakeholders. Business Sustainability extends the sustainability concepts which focuses on environment, social and governance (ESG) to measure business sustainability performance that consists of economic, governance, social, ethical and environmental (EGSEE). (Rezaee, 2015; Rezaee, Zhen, \& Ha, 2017). In literature the term business sustainability, corporate social responsibility (CSR), triple bottom line, environment, social and governance (ESG) have been used interchangeably. However, recently business sustainability is considered broader than CSR and even ESG. (Kiron et al., 2013; Rezaee, 2015; UN Global Compact, 2013; GRI, 2013). There are some grand theories that have been developed to explain sustainability measures from Friedman (1962) Shareholder Theory, Freeman (2010) Stakeholder Theory and Jensen (2011) Enlighten Value Maximation and Enlighten Stakeholder Theory. Among these theories, Stakeholder theory is one of the most frequently used approach in social, environmental, and sustainability management research (Frynas \& Yamahaki, 2013; Montiel \& Delgado-Ceballos, 2014). Stakeholder theory is often the starting point for analyses in a number of publications on corporate sustainability and sustainability management, no matter whether they are textbooks, research papers, or policy publications (e.g., Darnall et al., 2010; Doh \& Guay, 2006; Kolk \& Pinkse, 2007; Lee, 2011; PerezBatres et al., 2012; Sarkis, Gonzalez-Torre, \& Adenso-Diaz, 2010). Having discussed Sustainable Theory in general, the review continues with sustainability and the financial system studies. On the optimist side there is scholar like Siegel (2012) who argues that the future is bright. The approaching peak in population growth will result in "fewer, richer, greener" people. Some scholars debate different approaches to sustainability. Chichilnisky (2012) suggests that the role of economics is now to focus somewhat less on profits and more on the long-run survival of our species. Foxon et al. (2012) suggest applying "complexity economics" which is best thought of as a research program that seeks to draw on a range of thinking and approaches, rather than as a single coherent body of thought. Scott-Cato (2012) advocates Green economics, a study of the economy that takes a philosophical position characterized by a deep respect for nature. Linner and Selin (2013) found from their empirical study that The United Nations Conference on Sustainable Development (UNCSD) did little to advance institutional reforms, but that the initiative to formulate Sustainable Development Goals has the potential to significantly influence the sustainable development agenda. After discussing sustainability financial system, the study continues to discuss sustainable life insurance product as part of finance. In this regard, The UNEP Financial Initiative (FI) Principles for Sustainable Insurance (PSI) serve as a global framework for the insurance industry to address environmental, social and governance risks and opportunities. Sustainable insurance products could be defined as insurance products developed by considering sustainable insurance concepts. Sustainable Insurance has four principles: (1) embed (environmental, social and governance / ESG) issues in decision making; (2) collaborate with clients and business partners to raise awareness of ESG issues, manage risk and develop solutions; (3) work with governments, regulators and other stakeholders to promote action on ESG issues; and (4) demonstrate accountability and transparency in public disclosures on implementing the principles. United Nations defines sustainability as inextricably related to equity and fairness. Therefore, having discussed sustainability the review continues with fairness discussion. This starts with fair price as the key focus of sustainable product development. A fair price requires ethical behavior which means not to use a power position, less information or other conditions that may affect the stakeholder interest. Looking at equity of all stakeholder interest is a new pricing approach to develop life insurance product. Fundamental to this concept is the equity theory that states an exchange might be perceived as fair when the cost/benefit report is the same for all parties (Adams, 1965). Kahneman et al. (1986) proposed "dual entitlement" as the dominant norm of price fairness. According to Xia et al. (2004) fairness assessment is a comparative process between current price and a reference point. Depending on the comparative process used, many scholars classify the process into two types: distributive and procedural. Distributive fairness refers to how resources or rewards are 
allocated between the parties in a transaction, the measure in which there exists a fair report between the investment made and the reward received (Cox, 2001; Goodwin \& Ross, 1992). Procedural fairness refers to fairness of the procedure by which a certain decision is made, "to the process underlying and leading to the eventual returns" (Maxwell, 2002; Diller, 2008). Diller (2008) proposed a model that provides a concise representation of the multi-dimensional concept of price fairness. The model depicts seven components: distributive fairness, consistent behavior, personal respect and regard for partner, fair dealing, price honesty, price reliability and influence/right of co-determination.

From general fair pricing theory discussion, the review goes into more specific pricing life insurance product. In pricing life insurance product, there is a concept which is called actuarial fairness. The concept originates from an Aristotelian tradition in which fairness requires equality between the goods exchanged. When dealing with aleatory contracts (type of contract whose execution or performance depends on a contingency or an uncertain (random) event beyond the control of either party) this principle evolved into equality in risk (Heras, 2019): benefits and costs should be proportional to the risk assumed. The formalization of this principle brings about the concept of mathematical expectation. Landes (2015) remarks that one should distinguish between "insurance as the general cooperative arrangement among individuals based on risk pooling and specific arrangements where an insurer acts as an intermediary between policyholders." The first concept relates to underwriting. The second one according to Knight's terminology is insurer and insured do not face the same uncertainty (Knight, 1985). Regulators have an important role to play about fairness of insurance prices. However frequently there is an awkward situation for regulator in enforcing fairness that leads Avraham (2017) to conjecture that lacking clear normative frameworks to judge insurance fairness, the policy makers are working "in a complete legal mess," instead of making contribution. Having discussed sustainability and actuarial fairness, this study continues with the review of current Unit Linked pricing approach. The aims are to identify any gaps on the fairness. Company generally uses Deterministic Profit Testing (DPT) to price Unit Linked product. Profit Testing is defined in the "Encyclopedia of Actuarial Science" as "the process of assessing the profitability of an insurance contract in advance of it being written". Basically, DPT works similar to Net Present Value (NPV). NPV has been suggested as a theoretically sound and normatively capital budgeting technique by many corporate finance textbooks (e.g. Damodaran 1999, Brealey and Myers (2000). DPT usually uses Profit Margin (PM) as a profit criterion. It is defined as: ratio of the total NPV by the expected present value of premiums and is expressed as follows:

$$
\mathrm{PM}=\frac{\mathrm{NPV}}{\mathrm{EPV}[\text { Premiums }]}=\frac{\sum_{t=1}^{n} t-1 p_{x}^{00} \operatorname{Pr}_{t} v_{r}^{t}}{\sum_{t=0}^{n-1} t_{x}^{00} P_{t} v_{r}^{t}}
$$

where $\mathrm{Pr}_{\mathrm{t}}=$ Company Profit for the $\mathrm{t}^{\text {th }}$ year which corresponds to the period $(\mathrm{t}-1, \mathrm{t}]$.

${ }_{t-1} p_{x}^{00}=$ Probability that the insured still holds the policy at the beginning of the $\mathrm{t}^{\text {th }}$ year; so that he or she did not die, surrender, or exit by means of any other type of decrement.

$\mathrm{V}_{\mathrm{r}}=$ discount rate which is corresponding to an interest rate of $i_{\mathrm{r}}$ per year.

$\mathrm{P}_{\mathrm{t}}=$ Premium paid at time $\mathrm{t}$.

DPT assumes a fixed fund growth whereas in realy the it is dynamic. To address the weakness of DPT, Stochastic Profit Testing (SPT) is developed. SPT considers the fund return follows a certain probability distribution. Review of more than 20 literatures show that the modeling for volatility and stock return are mixed. The modeling depends on time horizon, crisis, daily or monthly data, etc. However, GARCH $(1,1)$ is frequently used. Since this study works with Jakarta Stock Exchange Composite Index (JCI), asymmetric GARCH (i.e. EGARCH) is also added as it is suggested by Singagerda (2019) and it also suggested by Andersson \& Haglund, 2015 for VaR risk measure forecasting. Therefore, this study will use GARCH $(1,1)$ and EGARCH $(1,1)$. With the probability distribution for the stock return, PM in SPT becomes in turn a stochastic variable with an associated probability distribution (Chapman \& Cooper, 1987; Ho \& Pike, 1992; Raftery, 1994). The most common practical way to do this is with Monte Carlo simulation. From each repeated run, we get a random sample of outcomes for the contract, which we can use to determine the probability distribution of the profit measure (PM) for the contract. (Aase \& Sandmann, 1995; Zaglauer \& Bauer, 2008; Rita \& Persson, 2002; Mahayni \& Steuten, 2013). According to equity and fairness distribution theory, fairness happens if the expected distribution of profit or loss between parties in the transaction is equal. In other words, the transaction should meet equity in risk. This leads to the use of Risk Measure to evaluate the fairness. There are many risk measures that has been studied by scholars. Among of them, Value at Risk (VaR) has changed the historical study of risk measurement as stated by the following studies: JP Morgan in 1994 created VaR to measure risk across the whole institution under one holistic risk measure (Dowd, 2002). In 1995, the Basel Committee on Banking Supervision stipulated a market risk capital based on VaR. This makes VaR becomes popular (Damelsson et al., 2004). Further study shows that VaR fails to meet coherent definition (Artzner et al., 1999). The Conditional Tail Expectation (CTE) was introduced to address some of the problems with the VaR. It becomes a popular risk measure when Basel Committee replaces VaR to this risk measure in 2013. Talking about profit and loss distribution, in actuarial applications Monte Carlo simulation is often used to estimate the loss distributions, particularly when the underlying processes are too complex for analytic manipulation such as profit testing model. Using standard Monte Carlo simulation, a large number of independent simulations of the loss random variable $\mathrm{L}$ is generated. Suppose we generate $\mathrm{N}$ such values, and order them from smallest to largest, such that $\mathrm{L}_{(\mathrm{j})}$ is the $\mathrm{j}$-th smallest simulated value of $\mathrm{L}$. We could assume 
the 'empirical' distribution of $\mathrm{L}_{(\mathrm{j})}$ is an estimate of the true underlying distribution of L (Hardy, 2006). The CTE is the mean of the worst $100(1-\alpha) \%$ of the loss distribution.

\section{Research Method}

The prime method to analyse the fairness is building financial modelling through SPT (Dickson et al., 2013) and using monte carlo. EXCEL macro is used to build the financial model. It is then validated with PROPHET actuarial software. R software is used for projection of GARCH $(1,1)$ and EGARCH $(1,1)$ model. The number of periods is 240 months $(20$ years) and the number of trials is 5000 . The fitted models for $\operatorname{GARCH}(1,1)$ and EGARCH $(1,1)$ are as follow:

\section{$\operatorname{GARCH}(1,1)$}

$$
r_{t}=0.009211+a_{t}, \quad a_{t} \sim \text { i.i.d. } N\left(0, \sigma_{t}^{2}\right) \quad \sigma_{t}^{2}=0.000463+0.254623 \varepsilon_{t-1}^{2}+0.511327 \sigma_{t-1}^{2}
$$

Here, $\sigma_{t}^{2}$ is the variance for the day $t . \varepsilon_{t}$ is the innovation for the day $t$.

\section{EGARCH $(1,1)$}

$r_{t}=0.009222+a_{t}, a_{t} \sim$ i.i.d. $N\left(0, \sigma_{t}^{2}\right), \ln \left(\sigma_{t}^{2}\right)=-1.584119+0.749690 \ln \left(\sigma_{t-1}^{2}\right)+0.394958\left(\left|z_{t-1}\right|-\mathbb{E}\left|z_{t-1}\right|\right)+0.115960 z_{t-1}$

where $\mathbb{E}\left|z_{t}\right|$ denotes the expected value of the absolute standard innovation, $z_{t}$, and is given by

$\mathbb{E}\left|z_{t}\right|=\int_{-\infty}^{\infty}\left|z_{t}\right| f(z, 0,1, \ldots) d z$

\subsection{Data Collection}

The target population for the study was any regular premium Unit Link product denominated in Rupiah currency. This research used simple random sampling as part of probability sampling techniques. From the population consisting of 34 companies 20 samples were drawn. Data is taken from the Indonesian Financial Service Authority (OJK). Data used are time period between 1 January 2015 to 30 June 2019. Each product is assumed to represent the pricing policy in terms of target profit of the company. For GARCH modelling the data comes from monthly Jakarta Composite Index from 1 April 1983 to 30 June 2019.

\subsection{Measurement}

P\&L is measured as Profit Margin (NPV of Profit before tax / NPV of Premiums) for both company and policyholder (PH). This study proposes the following definition for PH P\&L: First, PH premium is split into cost for insurance protection and investment; then the PH investment part is accumulated at company expected future growth of the investment fund. Company also accumulates the investment part; however, they deduct several charges into the fund. The difference between accumulated investment from $\mathrm{PH}$ and company is the P\&L for PH. Using this definition, the maximum profit for PH is zero. From the 5000 simulations, P\&L (PM) distribution for PH and company is generated. From the P\&L (PM) distribution, we could calculate CTE with $\alpha=10 \%$ (following IAA guideline for long term projection). Fairness is achieved when CTE for PH and Company falls under the range of criterion explained in Results section. If the CTE falls under the area which is expected to become narrower in the future, it means PH does not experience a very heavy charges and therefore high loss. Most of the time if CTE for $\mathrm{PH}$ getting closer to $0 \%$ in the area, then it will imply that CTE for company will get closer also to $0 \%$. The closer the CTE for $\mathrm{PH}$ to $0 \%$, the fairer the product will be. If the distribution of profit between $\mathrm{PH}$ and Company is fair under stress condition, it will be fairer under normal situation. The fair distribution on CTE should lead to the equity in risk; hence fairness. The result of CTE for PH and Company should be reported to regulator. CTE for PH should be made transparent in the selling process.

\subsection{Summary of the New Framework}

The following flowchart summarizes the new framework and at the same time show what enhancements it makes compared to existing framework.

\section{Results and Discussions}

This section discusses the achievement of three research objectives and answer to the research questions.

\subsection{Main Findings from Current Practice on the Profit Testing Results}

The results of Profit Margin (PM) from the profit testing for the 20 samples are presented under Table 1.

Results are presented under DPT and two SPTs i.e. GARCH and EGARCH. 


\begin{abstract}
Current Practice. Few companies have used SPT. Only focuses on company Profit Margin.
\end{abstract}

New enhancement by adding profitability for policyholder. Introducing risk measurement CTE as a fairness criterion.

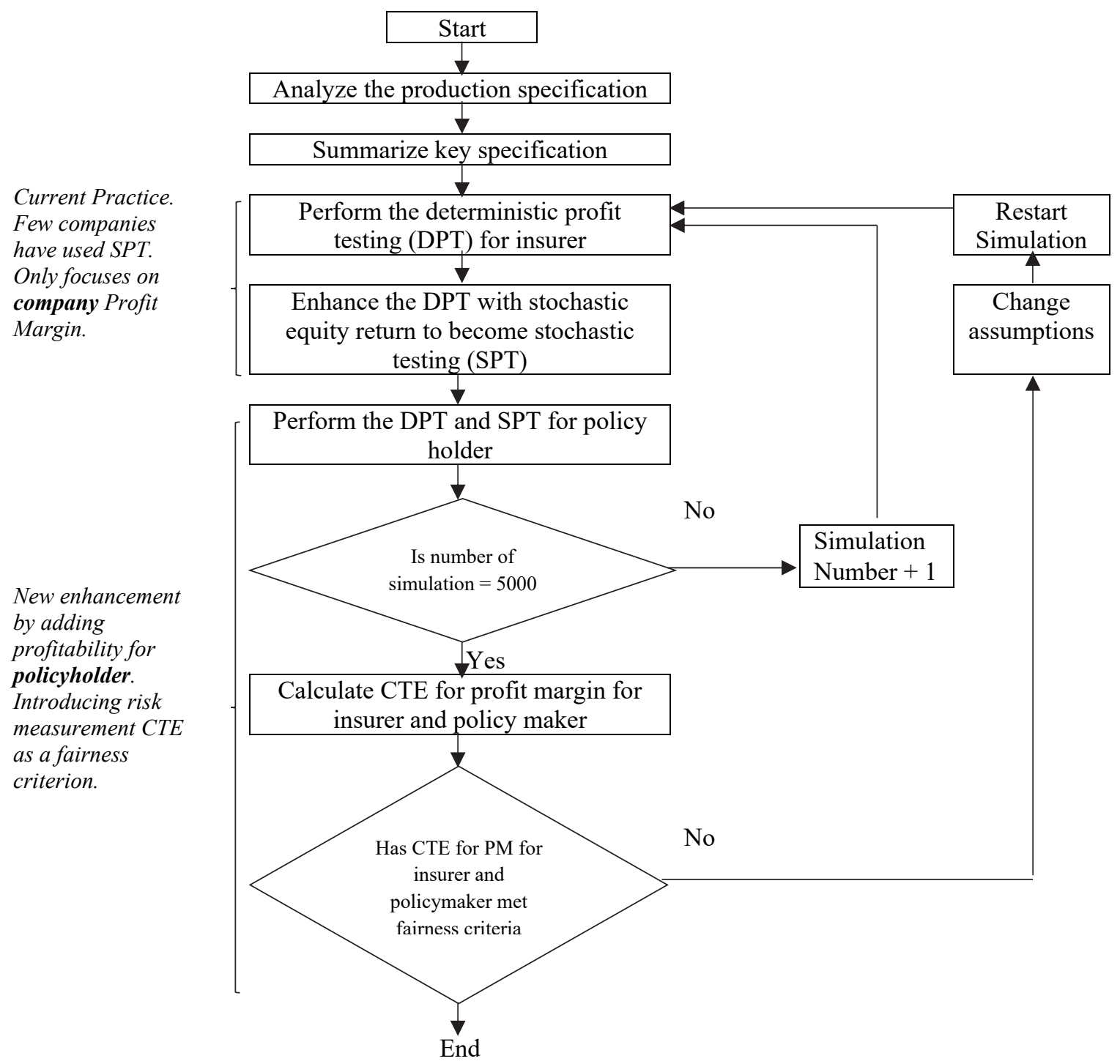

Table 1

Profit Margin (PM) under Several Scenarios

\begin{tabular}{|c|c|c|c|}
\hline Product $\backslash$ Scenario & PM-DPT & PM-GARCH & PM-EGARCH \\
\hline 2 & $23.45 \%$ & $23.64 \%$ & $23.63 \%$ \\
\hline 3 & $8.65 \%$ & $12.63 \%$ & $12.57 \%$ \\
\hline 4 & $15.12 \%$ & $16.02 \%$ & $16.00 \%$ \\
\hline 5 & $13.31 \%$ & $11.47 \%$ & $11.41 \%$ \\
\hline 6 & $9.30 \%$ & $9.56 \%$ & $9.54 \%$ \\
\hline 7 & $21.18 \%$ & $22.02 \%$ & $22.00 \%$ \\
\hline 8 & $11.49 \%$ & $12.35 \%$ & $12.36 \%$ \\
\hline 11 & $20.06 \%$ & $22.18 \%$ & $22.15 \%$ \\
\hline 13 & $11.03 \%$ & $12.40 \%$ & $12.34 \%$ \\
\hline 14 & $18.73 \%$ & $19.36 \%$ & $19.34 \%$ \\
\hline 15 & $14.64 \%$ & $15.38 \%$ & $15.35 \%$ \\
\hline 16 & $13.10 \%$ & $13.41 \%$ & $13.38 \%$ \\
\hline 18 & $16.73 \%$ & $17.71 \%$ & $17.67 \%$ \\
\hline 19 & $7.01 \%$ & $8.57 \%$ & $8.52 \%$ \\
\hline 23 & $16.65 \%$ & $17.28 \%$ & $17.26 \%$ \\
\hline 24 & $5.31 \%$ & $5.80 \%$ & $5.77 \%$ \\
\hline 25 & $14.98 \%$ & $15.62 \%$ & $15.77 \%$ \\
\hline 26 & $13.14 \%$ & $13.97 \%$ & $13.93 \%$ \\
\hline 27 & $12.44 \%$ & $15.65 \%$ & $15.61 \%$ \\
\hline 28 & $13.92 \%$ & $14.30 \%$ & $14.29 \%$ \\
\hline
\end{tabular}


The average gross PM under DPT scenario is $14.01 \%$. This study will provide two benchmarks to judge this result. First benchmark is taken from the net interest margin for banks in Indonesia from first quarter 2014 to fourth quarter 2018. The hypothesis testing for Life Insurance PM is higher than Banks NIM (gross up with 25\% tax) result is as follow:

Table 2

Life Insurance PM versus Bank NIM (gross up with 25\% tax)

\begin{tabular}{ccccc} 
& Insurance & All Banks & Private Banks & State-Owned Banks \\
\hline $\mathbf{N}$ & 20 & 1920 & 1060 & 140 \\
Average & $14.01 \%$ & $7.63 \%$ & $7.22 \%$ & $8.39 \%$ \\
p-value & & 0.00000 & 0.00000 & $5.45 \%$ \\
\hline
\end{tabular}

Source: Indonesia Banking Directory 2018

All the p-values are significant which mean that Life Insurance PM is higher than Banks NIM (gross up with $25 \%$ tax). The second benchmark comes from life insurance industry outside Indonesia. According to Sardon (2019), the average financial industry (banks and insurances) profit margin (before tax) in US is $5.8 \%$. China Life (the biggest life insurance company) net profit margin as of September 30, 2019 is $7.02 \%$ which is the highest since 2016. If we use corporate tax $21 \%$, the gross profit margin for China Life becomes $9.36 \%$. From the two benchmarks above, it shows that PM life insurance industry is relatively high. Using SPT (either GARCH or EGARCH) does not change DPT profit margin significantly. Therefore, company is suggested to use SPT since this method provides more information about the distribution of the result than DPT. At the same time, the final decision about the profitability of the product is about the same. GARCH and EGARCH produce almost the same result. This is an important result that shows the choice of econometric model between GARCH and EGARCH will not have a significant impact on the result. However, further research needs to be done to extend the results to other GARCH and asymmetric GARCH family.

\subsection{Main Findings on The Fairness Problems from Current Practice}

The analysis about the product assumptions and profit testing results will raise several questions if we measure against the literature review about fairness and sustainability. The next section will discuss them in detail.

\subsubsection{Lack of Stakeholder Interest}

From the sample data assumptions setting, it could be deduced that current practice is lacking stakeholder consideration especially policyholder. For example, the average allocation rate is $43 \%$. This means that $57 \%$ of the money are not invested and used to pay several costs. It will take a long time for policyholder even to break even. Average commission rate is $55 \%$ with distributor bears little risk other than their operational cost. All of these treatments resulted in a high percentage of lapse in the first year which average is $19 \%$. This practice raises a question whether business create value for all stakeholders as suggested by Freeman (2010) Stakeholder theory.

\subsubsection{Creating Non-Sustainable Financial System}

The high cost assumptions such as lower allocation, high commission, high supplementary fee, high surrender charge, etc. are examples of short-term focus on company and distributor profit. It lacks of long-term view. Therefore, it is not in-line with scholars who believe in sustainable economic growth such as Chichilnisky (2012), Scott Cato (2012) and Kallis (2011). All of this will not help insurance to play a role in the financial system as a risk management or financial planning tool.

\subsubsection{Lack of UNEP FI Sustainable Insurance Principles}

Reviewing current product development including all the assumptions setting shows that it lacks of social (policyholder) issues. The higher commission rate seems to show that company does not collaborate with distributor to promote ESG. The justifications for the assumptions are seldom communicated to regulators let alone policyholders. Overall, current process does not support accountability and transparency on implementing the sustainability insurance principles. This finding is in line with Linner \& Selin (2013) who found that The United Nations Conference on Sustainable Development (UNCSD) has not done much to advance institutional reforms.

\subsubsection{Lack of Fair Pricing Concepts}

If we measure current practice against several price fairness dimensions, it lacks many of them. The pricing procedure is not transparent. For example, why company have to allocate a low percentage on the investment fund, and impose high surrender charge. The common reason given is the high acquisition cost, but why the acquisition cost is so high. What kind of acquisition cost are we referring to? This kind of issues are frequently not made transparent in the selling process. In Maxwell (2002) and Diller (2008) terms, the process underlying and leading to the eventual results lacks of procedural fairness.

\subsubsection{Lack of Actuarial Fairness}

It is true that all of us face uncertainty in the fund performance. The question is: does company faces the same uncertainty as the policyholder does? Could regulator check against this as part of customer protection? Unfortunately, current practices do 
not seem to address those questions. Most of the companies do not explain how they price the uncertainty of fund performance. According to Knight (1985) current process seldom take into consideration equitable contract. The absence of any criteria to measure profit/loss for policyholder makes it difficult to judge whether the distribution of profit and loss meets the equity principle (Chong, 2015; Kamas and Preston, 2012).

\subsubsection{Lack of Equity in term of Risk Measure}

Current practice only use mean as the target return. It does not have transparent and objective risk measure. Therefore, it is difficult to judge whether it meets equity of risk between company and policyholder. Given all the charges, is it fair to policyholder to bear all the uncertainty in the fund performance? (Barnard et al., 2018).

\subsection{Development of Risk Measurement in the New Framework and the Results}

From previous section, there are some improvements that need to be developed in the new pricing framework. The new framework needs to consider all stakeholders involved especially policyholder. It should have PM for policyholder consideration in the profit testing not only company. It should have a quantitative measurement in the form of reference point for policyholder and regulator to judge the relative fairness of a product. All the improvements identified lead this study to develop Conditional Tail Expectation (CTE) risk measure generated from the new framework to price a product. CTE will provide company and policyholder about the relative fairness of the product based on equity in risk principle. CTE in the new framework will address the issues in current pricing since: (1) It considers profitability for company and policyholder, (2) It measures the average loss of the PM distribution for company and policyholder, therefore it could be used to achieve equity in risk, (3) It is a quantitative measurement that could be used as a reference point and can be made transparent, (4) Finally, it is a coherent risk measure and is recommended by both Basel and International Actuarial Association.

The next section will discuss the results of the new framework.

The first step in understanding the new framework is to look at the results of PM after the introduction of policyholder profitability in the profit testing. The mean of PM distribution under SPT for company and policyholder is presented in Table 3 as follows,

Table 3

The Mean of PM distribution under SPT for Company and Policyholder

\begin{tabular}{|c|c|c|c|c|c|c|}
\hline \multirow[t]{3}{*}{ Product $\backslash$ Statistics } & \multicolumn{2}{|c|}{$\mathbf{N}$} & \multicolumn{4}{|c|}{ Mean } \\
\hline & \multirow[b]{2}{*}{ GARCH } & \multirow[b]{2}{*}{ EGARCH } & \multicolumn{2}{|c|}{ Company } & \multicolumn{2}{|c|}{ Policyholder } \\
\hline & & & GARCH & EGARCH & GARCH & EGARCH \\
\hline 2 & 4,964 & 4,975 & $23.64 \%$ & $23.63 \%$ & $-124.89 \%$ & $-123.57 \%$ \\
\hline 3 & 4,849 & 4,876 & $12.63 \%$ & $12.57 \%$ & $-59.83 \%$ & $-58.87 \%$ \\
\hline 4 & 5,000 & 5,000 & $16.02 \%$ & $16.00 \%$ & $-77.03 \%$ & $-76.19 \%$ \\
\hline 5 & 4,984 & 4,992 & $11.47 \%$ & $11.41 \%$ & $-37.43 \%$ & $-37.13 \%$ \\
\hline 6 & 4,660 & 4,686 & $9.56 \%$ & $9.54 \%$ & $-88.65 \%$ & $-87.78 \%$ \\
\hline 7 & 4,384 & 4,428 & $22.02 \%$ & $22.00 \%$ & $-113.84 \%$ & $-112.39 \%$ \\
\hline 8 & 5,000 & 5,000 & $12.35 \%$ & $12.36 \%$ & $-45.15 \%$ & $-44.89 \%$ \\
\hline 11 & 4,997 & 4,997 & $22.18 \%$ & $22.15 \%$ & $-82.80 \%$ & $-81.63 \%$ \\
\hline 13 & 4,036 & 4,059 & $12.40 \%$ & $12.34 \%$ & $-119.86 \%$ & $-117.36 \%$ \\
\hline 14 & 4,019 & 4,037 & $19.36 \%$ & $19.34 \%$ & $-119.72 \%$ & $-118.26 \%$ \\
\hline 15 & 5,000 & 5,000 & $15.38 \%$ & $15.35 \%$ & $-134.38 \%$ & $-133.12 \%$ \\
\hline 16 & 4,708 & 4,765 & $13.41 \%$ & $13.38 \%$ & $-113.81 \%$ & $-112.43 \%$ \\
\hline 18 & 4,870 & 4,892 & $17.71 \%$ & $17.67 \%$ & $-47.05 \%$ & $-46.57 \%$ \\
\hline 19 & 5,000 & 5,000 & $8.57 \%$ & $8.52 \%$ & $-87.81 \%$ & $-86.89 \%$ \\
\hline 23 & 5,000 & 5,000 & $17.28 \%$ & $17.26 \%$ & $-72.51 \%$ & $-71.75 \%$ \\
\hline 24 & 4,445 & 4,481 & $5.80 \%$ & $5.77 \%$ & $-127.53 \%$ & $-125.72 \%$ \\
\hline 25 & 4,819 & 4,840 & $15.62 \%$ & $15.77 \%$ & $-87.95 \%$ & $-89.43 \%$ \\
\hline 26 & 4,723 & 4,740 & $13.97 \%$ & $13.93 \%$ & $-93.66 \%$ & $-92.44 \%$ \\
\hline 27 & 5,000 & 5,000 & $15.65 \%$ & $15.61 \%$ & $-58.14 \%$ & $-57.49 \%$ \\
\hline 28 & 4,985 & 4,993 & $14.30 \%$ & $14.29 \%$ & $-105.59 \%$ & $-104.52 \%$ \\
\hline
\end{tabular}

Similar to DPT, GARCH and EGARCH produces a similar result. Is there a relationship between mean/average of PM distribution for company and for policyholder? Fig. 1 shows details of the correlation between mean and policyholder. The correlation coefficient is -0.11 which means there is no correlation between the mean/average of PM distribution for company and policyholder. This means that it is not sufficient for company to stop the pricing process only until company point of view. Company needs to run profit testing for policyholder (enlighten profit testing) from the new framework, since there is no guarantee if lower company PM will produce lower loss for policyholder. The average SPT mean for policyholder is $-90 \%$ which is very far from $0 \%$. Again, this finding shows that average industry product is far from fair to policyholder. Finally, this study will discuss the main finding from CTE as risk measure for equity between company and policyholder. 


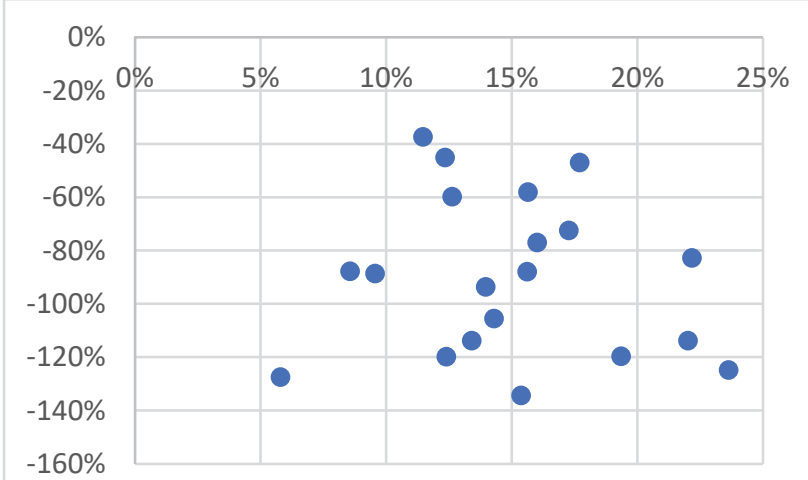

Fig. 1. The results of Mean versus policyholder

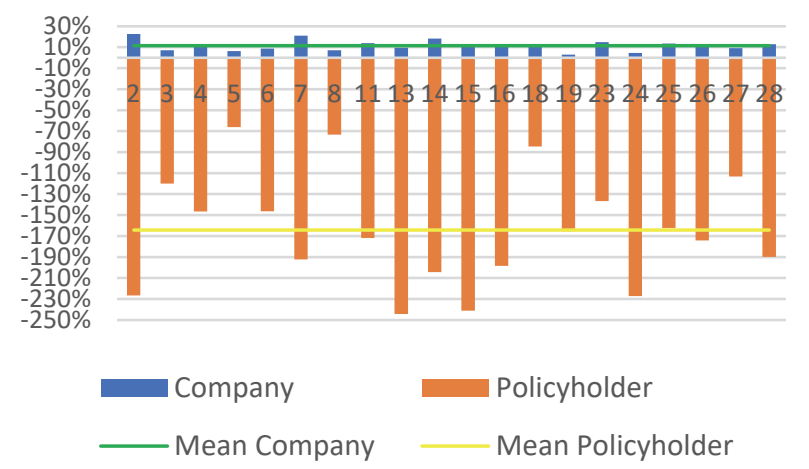

Fig. 2. CTE for Company and Policyholder

The bigger the distance between the top of blue bar and the bottom of the brown bar, the less fair the product is. The industry (in other words the whole products) is becoming fairer if the distance between green line (average company) and yellow line (average policyholder) is getting narrower and narrower. The average CTE for company (green line) is $11.67 \%$ and the average CTE for policyholder (yellow line) is $-164.24 \%$.

Table 4

CTE Result for Company and Policyholder

\begin{tabular}{|c|c|c|c|c|}
\hline \multirow[t]{3}{*}{ Product $\backslash$ Statistics } & \multicolumn{4}{|c|}{ CTE $\alpha=10 \%$} \\
\hline & \multicolumn{2}{|c|}{ Company } & \multicolumn{2}{|c|}{ Policyholder } \\
\hline & GARCH & EGARCH & GARCH & EGARCH \\
\hline 2 & $22.54 \%$ & $22.57 \%$ & $-226.58 \%$ & $-214.49 \%$ \\
\hline 3 & $7.04 \%$ & $7.04 \%$ & $-119.91 \%$ & $-112.43 \%$ \\
\hline 4 & $12.47 \%$ & $12.55 \%$ & $-146.66 \%$ & $-138.49 \%$ \\
\hline 5 & $6.24 \%$ & $6.27 \%$ & $-66.17 \%$ & $-62.89 \%$ \\
\hline 6 & $8.61 \%$ & $8.61 \%$ & $-146.37 \%$ & $-139.53 \%$ \\
\hline 7 & $21.01 \%$ & $21.00 \%$ & $-192.28 \%$ & $-182.36 \%$ \\
\hline 8 & $7.05 \%$ & $7.10 \%$ & $-73.36 \%$ & $-70.70 \%$ \\
\hline 11 & $13.77 \%$ & $13.71 \%$ & $-171.84 \%$ & $-160.88 \%$ \\
\hline 13 & $9.58 \%$ & $9.61 \%$ & $-244.37 \%$ & $-227.24 \%$ \\
\hline 14 & $18.27 \%$ & $18.27 \%$ & $-204.37 \%$ & $-193.39 \%$ \\
\hline 15 & $12.69 \%$ & $12.73 \%$ & $-241.16 \%$ & $-228.50 \%$ \\
\hline 16 & $12.25 \%$ & $12.25 \%$ & $-198.45 \%$ & $-187.63 \%$ \\
\hline 18 & $12.68 \%$ & $12.70 \%$ & $-84.73 \%$ & $-80.30 \%$ \\
\hline 19 & $2.96 \%$ & $3.15 \%$ & $-165.40 \%$ & $-156.18 \%$ \\
\hline 23 & $14.79 \%$ & $14.88 \%$ & $-136.60 \%$ & $-128.99 \%$ \\
\hline 24 & $4.53 \%$ & $4.51 \%$ & $-227.12 \%$ & $-214.33 \%$ \\
\hline 25 & $13.47 \%$ & $13.55 \%$ & $-162.23 \%$ & $-148.23 \%$ \\
\hline 26 & $11.40 \%$ & $11.41 \%$ & $-174.19 \%$ & $-164.15 \%$ \\
\hline 27 & $9.09 \%$ & $9.16 \%$ & $-113.16 \%$ & $-106.66 \%$ \\
\hline 28 & $12.94 \%$ & $12.97 \%$ & $-189.88 \%$ & $-179.97 \%$ \\
\hline
\end{tabular}

Is there a relationship between risk measure CTE and mean PM for Company and Policyholder?

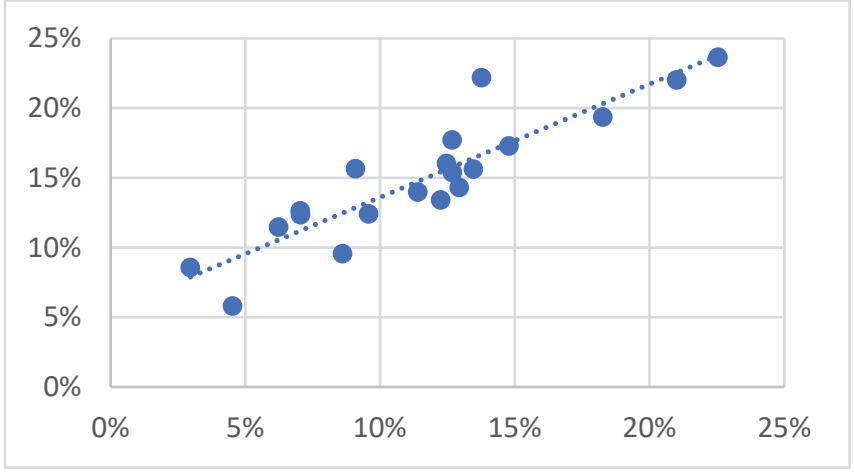

Fig. 3. Correlation between CTE and Mean of PM for Company

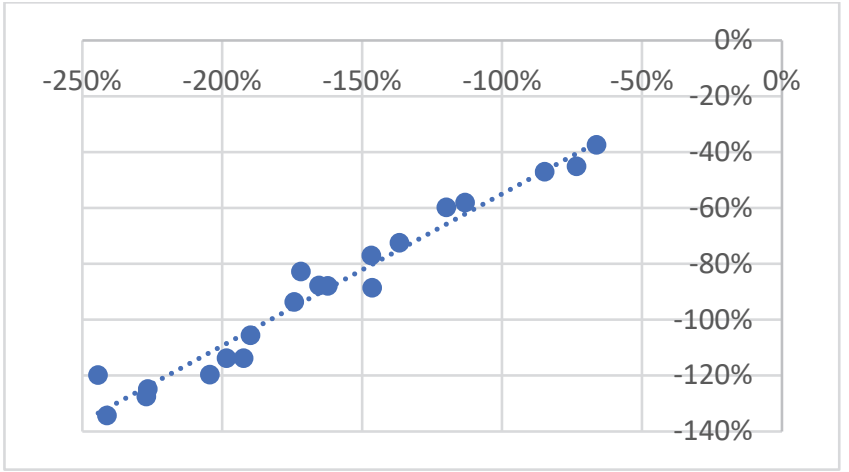

Fig. 4. Correlation between CTE and Mean of PM for Policyholder 
The correlation coefficient is 0.90 which means the two variables are strongly correlated. If companies want to be fairer, then they have to reduce their mean PM. Since the mean is strongly correlated with the CTE, companies could also be fairer by reducing their CTE. If company reduces their CTE, then the green line will move closer to the yellow line in Fig. 2. The correlation coefficient is 0.98 . This means that company could use CTE also instead of mean PM* to investigate the fairness of its product. Fig. 3 and Fig. 4 show that company could use CTE and arrive at the same decision as it uses the mean PM. In current practice company only does profit testing maximum until SPT and use the mean of PM to make a decision. Since CTE is strongly correlated to the mean, therefore company could use CTE to arrive at the same decision. Hence CTE is a more informative measurement than the mean and at the same time is consistent with current company practice to make a decision. This is an important result that shows the new framework is a superset of current existing framework.

\section{Conclusions and Recommendations}

Assumptions used in current pricing arguably do not support fairness consideration for policyholder. The PM result seems too high compared to banks. Current practice is also lacking of policyholder interest, fair pricing concepts and actuarial fairness. It does not create sustainable financial system and sustainable insurance principles. It doesn't have a reference point to assess relative fairness of a product. New framework proposes to consider stakeholder pricing by introducing PM for policyholder. New framework also enhances the current profit testing so it could generate a reference point CTE to assess relative fairness of a product. Using CTE, company and policyholder could achieve equity in risk therefore fairness. There are several implications arising from this study. First, it creates a new Unit Linked pricing framework that shifts the paradigm that focus only on company to include profit/loss (or risk) for policyholder. By shifting the return paradigm to risk paradigm, equity in risk could be established. Second, it contributes to regulators so they could have a reference point to assess a unit linked product. Third, it contributes to policyholders so they could compare the products in the market. Finally, the trust to company will increase and as a result company could sell a complex product like unit linked through on line which at the end will foster the growth of the industry. Another important conclusion from this study is that the proposed framework is a superset of current framework. It means that company could use CTE as a criterion and arrives at the same decision with current framework which uses PM. Besides that, CTE will provide fairness information to company which does not exist under current framework. This study suggests several recommendations for all stakeholders in the life insurance industry. For companies, they need to be more efficient in their operation cost and distribution cost. The recent COVID-19 pandemic force company to speed up the transformation of the way they are doing business. One of the most frequently suggested way is to adopt digital transformation. McKinsey (2016) identify a potential reduction of $45 \%-65 \%$ reduction in administrative expense. If company could be more efficient by $50 \%$ from current status, then the CTE chart will change as follow (using only 5 companies as example):
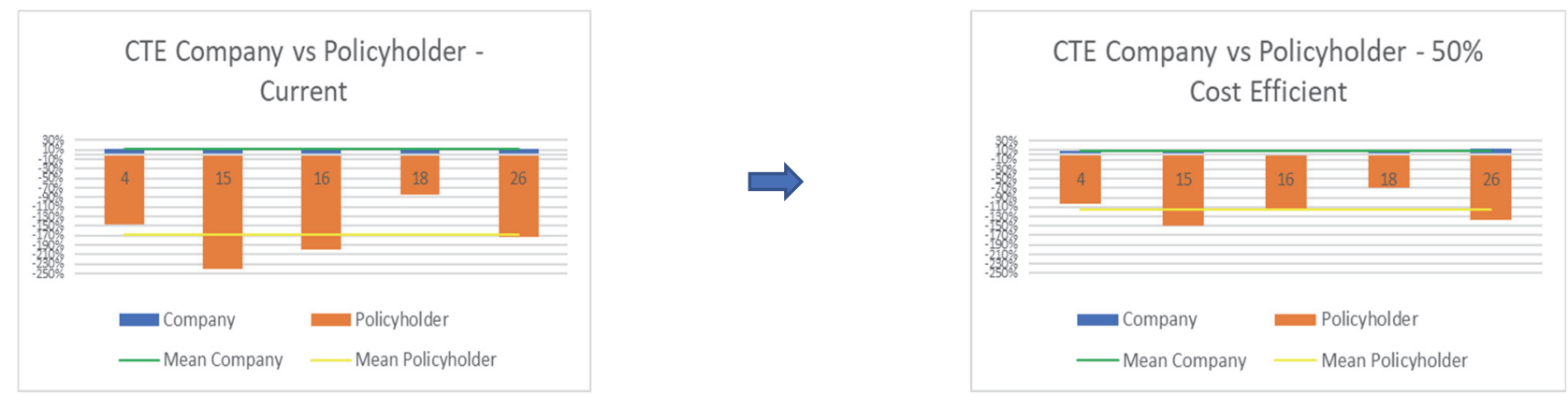

The CTE company does not change much but CTE policyholder changes from $-170 \%$ to $-110 \%$ which means that the product becomes fairer eventhough it has not achieved an ideal situation. As company becomes more efficient then the wide of the ribbon between green and yellow line becomes narrower and narrower. Regulator could be more active driving the industry towards narrowing the wide of the ribbon by setting a specific timeframe of compliance at specific time. This requirement could be part of Sustainability Report as imposed by many regulators nowadays. In order to launch the first time CTE for company and policyholder reference point, it is recommended that regulator uses more sample products from the industry. Eventhough this study finds that a radical change is needed, an incremental change is more palatable to the industry. Initially, regulator with industry should agree on certain number or range for CTE company and policyholder. These starting reference points will be reviewed regularly until regulator and industry think that an acceptable number has been achieved. The CTE should be reported in the sustainability report and audited regularly.

\section{References}

Aase Nielsen, J., \& Sandmann, K. (1995). Equity-linked life insurance: A model with stochastic interest rates. Insurance: Mathematics and Economics, 16(3), 225-253.

Adams, J. S. (1965). Inequity in social exchange. Advances in experimental social psychology, 2, 267-299, New York: Academic Press. 
Andersson, O., \& Haglund, E. (2015). Financial Econometrics: A Comparison of GARCH type Model Performances when Forecasting VaR. Bachelor of Science Thesis.

Artzner, P., Delbaen, F., Eber, J., \& Heath, D. (1999). Coherent measure of risk. Mathematical Finance, 9(3), $203-228$.

Avraham, R. (2017). Discrimination and Insurance. SSRN Scholarly Paper ID 3089946.

Barnard, C. R., Francis, K., Hussain, T., Jumanca, C., \& Zhang, A. (2018). How can we improve the customers' experience of our life products? British Actuarial Journal, 23.

Brealey, R. \& Myers, S.C. (2000). Principles of Corporate Finance (McGraw-Hill: New York).

Cato, M. S. (2012). Green economics: putting the planet and politics back into economics. Cambridge Journal of Economics, 36(5), 1033-1049.

Chapman, D., \& Cooper, C. (1987). Risk analysis for large projects: models, methods \& cases. New York: John Wiley \& Sons.

Chichilnisky, G. (2012). Economic theory and the global environment. Economic Theory, 49(2), $217-225$.

Chong, M. L. (2015). The effects of nonfinancial performance measures on role clarity, procedural fairness and managerial performance. Pacific Accounting Review, 27(2), 142-165.

Cox, J. L. (2001). Can differential prices be fair?. Journal of Product and Brand Management, 50(5), $264-75$.

Damelsson, J., Shin, H.S. and Zigrand, J.P. (2004). The impact of risk regulation on price dynamics. Journal of Banking and Finance, 25, 1069-1087.

Damodaran, A. (1999). Applied Corporate Finance: A User's Manual (Wiley: New York).

Darnall, N., Henriques, I. \& Sadorsky, P. (2010). Adopting proactive environmental strategy: The influence of stakeholders and firm size, Journal of Management Studies, 47, 1072-1094.

Dickson, D. C. M., M. R. Hardy, \& H. R. Waters. (2013). Actuarial Mathematics for Life Contingent Risks. Cambridge University Press, 2 edn.

Diller, H. (2008). Price fairness. Journal of Product \& Brand Management, 17(5), 353-355.

Doh, J. P. \& Guay, T. R. (2006). Corporate social responsibility, public policy, and NGO activism in Europe and the United States: An institutional-stakeholder perspective, Journal of Management Studies, 43(1), 47-73.

Dowd, K. (2002). An Introduction to Market Risk Measurement. NJ: J. Wiley Hoboken.

Ferguson, J. L., Ellen, P. S. \& Bearden, W. O. (2014). Procedural and distributive fairness: Determinants of overall price fairness. Journal of Business Ethics, 121, 217-231.

Financial Conduct Authority. (2018). Climate Change and Green Finance, Discussion Paper.

Foxon, T. J., Kohler, J., Michie, J. \& Oughton, C. (2012). Towards a new complexity economics for sustainability. Cambridge Journal of Economics, 37(1), 187-208.

Freeman, R. E. (2010). Stakeholder theory. The state of the art, Cambridge: Cambridge University Press.

Friedman, M. (1962). Capitalism and freedom. Chicago: University of Chicago Press.

Friedman, M. (1970). The social responsibility of business is to increase its profits. New York Times Magazine, 32-33, 122, 124, 126.

Frynas, J. G. \& Yamahaki, C. (2013). Corporate social responsibility: Review and roadmap of theoretical perspectives, Paper presented at the BAM2013 Conference Proceedings, Liverpool, England.

Gerard, B. (2018). ESG and Socially Responsible Investment: A Critical Review, SSRN Electronic Journal.

Goodwin, C. \& Ross, I. (1992). Consumer responses to service failure: influence of procedural and interactional fairness perceptions, Journal of Business Research, 25(2), 149-163

Hallstedt, S. (2017). Sustainability criteria and sustainability compliance index for decision support in product development. Journal of Cleaner Production, 140, 251-266.

Hardy, M. (2006). An Introduction to Risk Measures for Actuarial Applications, Casualty Actuarial Society and the Society of Actuaries.

Heras, A., M., Teira, D., \& Pradier, P., C. (2016). What was fair in actuarial fairness?, Documents de travail du Centre d'Economie de la Sorbonne 16073, Université Panthéon-Sorbonne (Paris 1), Centre d'Economie de la Sorbonne.

Hira, T. K. (2012). Promoting sustainable financial behaviour: implications for education and research, International Journal of Consumer Studies, 36(5), 502-507.

Ho, S. S. M. \& Pike, R. H. (1992). The use of risk analysis technique in capital investment appraisal. New York: John Wiley $\&$ Sons.

Jensen, M. (2011). Value Maximization, stakeholder theory and the corporate objective function. Journal of applied corporate finance, $14(3)$.

Kahneman, D., Knetsch, J. L., \& Thaler, R. (1986). Fairness as a constraint on profit seeking: Entitlements in the market. The American Economic Review, 76(4), 728-741

Kallis, G. (2011). In defence of degrowth. Ecological Economics, 70(5), 873-880

Kamas, L., \& Preston, A. (2012). Distributive and reciprocal fairness: What can we learn from the heterogeneity of social preferences?. Journal of Economic Psychology, 33(3), 538-553.

Kiron, D., Kruschwitz, N., Haanaes, K., Reeves, M. \& Goh, E. (2013). The innovation bottom line: The benefit of sustainabilitydriven innovation. MIT Sloan Management Review and the Boston Consulting Group Research Paper, 54(2), 69-73.

Knight, F. H. (1985). Risk, uncertainty and profit. Chicago: University of Chicago press. 
Kolk, A., \& Pinkse, J. (2007). Towards strategic stakeholder management? Integrating perspectives on sustainability challenges such as corporate responses to climate change. Corporate Governance International Journal of Business Society, 7, 370378.

Krawczyk, M., W. (2011). A model of procedural and distributive fairness. Theory and Decision, 70(1), 111-128.

Landes, X. (2015). How fair is actuarial fairness. Journal of Business Ethics, 128(3), 519-533.

Lee, M.-D. P. (2011). Configuration of external influences: The combined effects of institutions and stakeholders on corporate social responsibility strategies. Journal of Business Ethics, 102, 281-298.

Linnér, B.-O., \& Selin, H. (2013). The United Nations Conference on Sustainable Development: Forty Years in the Making. Government and Policy, 31(6), 971-987.

Lucas, T. (2009). Justifying outcomes versus processes: Distributive and procedural justice beliefs as predictors of positive and negative affectivity. Current Psychology, 28(4), 249-265.

Lys, T., Naughton, J. \& Wang, C. 2015, Signaling through corporate accountability reporting, Journal of Accounting and Economics, 60(1), 56-72

Mahayni, A. \& Steuten, D. (2013). Deferred life annuities: on the combined effects of stochastic mortality and interest rates. Review of Managerial Science, 7(1), 1-28.

Maxwell, S. (2002). Rule-based price fairness, and its effect on willingness to purchase. Journal of Economic Psychology, 23(2), $191-212$

McKinsey. (2016). Harnessing the Power Of Digital in Life Insurance, Financial Service Practice report.

Montiel, I. \& Delgado-Ceballos, J. (2014). Defining and measuring corporate sustainability: Are we there yet? Organization \& Environment, Advance online publication.

Perez-Batres, L. A., Doh, J. P., Miller, V. \& Pisani, M. J. (2012). Stakeholder pressures as determinants of CSR strategic choice: Why do firms choose symbolic versus substantive self-regulatory codes of conduct? Journal of Business Ethics, 110, 157172.

Raftery, J. (1994). Risk analysis in project management, London: E\&FN Spon.

Reisman, R., Payne, A. \& Frow, P. (2019). Pricing in consumer digital markets: A dynamic framework, Australasian Marketing Journal (AMJ).

Rezaee, Z. (2015), Business sustainability research: A theoretical and integrated perspective. Journal of Accounting Literature, $36,48-64$.

Rezaee, Z., Zhen, K. \& Ha, M. (2017). Progress Toward Business Sustainability in Asia in the Aftermath of 2015 Hong Kong Stock Exchange Requirements. International Journal of Sustainability Management and Information Technologies, 3(4), 40-45.

Rita, B. A., \& Persson, S. (2002). Design and pricing of equity-linked life insurance under stochastic interest rates. The Journal of Risk Finance, 3(2), 6-21.

Sardon, M. (2019). Financial Industry Leads the Way on Diversity and Inclusion, The Wall Street Journal Oct $26,2019$.

Sarkis, J., Gonzalez-Torre, P. \& Adenso-Diaz, B. (2010). Stakeholder pressure and the adoption of environmental practices: The mediating effect of training. Journal of Operations Management, 28, 163-176.

Siegel, L. B. (2012). Fewer, richer, greener: The end of the population explosion and the future for investors. Financial Analysts Journal, 68(6), 20-37.

Singagerda, F., S., Septarina, L., \& Sanusi, A. (2019). The volatility model of the ASEAN Stock Indexes. Investment Management and Financial Innovations, 16(1), 226-238.

United Nations Global Compact (UN Global Compact). (2013). Global corporate sustainability report.

Weber, O. (2014). The financial sector's impact on sustainable development. Journal of Sustainable Finance \& Investment, $4(1), 1-8$.

World Commission on Environment and Development (WCED). (1987). The Brundtland Report: our common future, Oxford: Oxford University Press 43.

Xia, L., Monroe, K. B. \& Cox, J. L. (2004). The price is unfair! A conceptual framework of price fairness perceptions. Journal of Marketing, 68(4), 1-15.

Zaglauer, K., \& Bauer, D. (2008). Risk-neutral valuation of participating life insurance contracts in a stochastic interest rate environment. Insurance: Mathematics and Economics, 43(1), 29-40.

Zhang, W. (2015). Perceived Procedural Fairness in Deliberation: Predictors and Effects. Communication Research, 42(3), 345364.

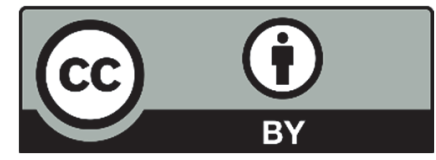

(C) 2021 by the authors; licensee Growing Science, Canada. This is an open access article distributed under the terms and conditions of the Creative Commons Attribution (CC-BY) license (http://creativecommons.org/licenses/by/4.0/). 